\title{
Desplazamiento forzado y mercado laboral en las principales ciudades de Colombia ${ }^{1}$
}

\section{Forced Displacement and the Labor Market in the Main Cities of Colombia}

\author{
Germán Darío Valencia-Agudelo² \\ Profesor titular del Instituto de Estudios Políticos de la Universidad de Antioquia, Medellín, Colombia \\ german.valencia@udea.edu.co \\ ORCID: http://orcid.org/0000-0002-6412-6986 \\ Juan David Montoya-Polanco 3 \\ Egresado de la Facultad de Ciencias Económicas de la Universidad de Antioquia, Medellín, Colombia \\ juanmonto5@gmail.com \\ ORCID: http://orcid.org/0000-0003-4747-3967 \\ Davidson Loaiza-Mejía \\ Egresado de la Facultad de Ciencias Económicas de la Universidad de Antioquia, Medellín, Colombia \\ davidson.loaiza@gmail.com \\ ORCID: http://orcid.org/0000-0002-5696-2554
}

Recibido: $15-02-2018$ Aprobado: 20-03-2019

\footnotetext{
1 Este artículo contó con el apoyo de la Estrategia de Sostenibilidad 2018-2019 del grupo Hegemonía, Guerras y Conflictos del Instituto de Estudios Políticos de la Universidad de Antioquia y hace parte de las dinámicas de trabajo que realiza la línea de investigación Conflicto armado, Paz negociada y Posconflicto.

2 Doctor en Estudios Políticos.

3 Economista.

4 Economista.
} 


\section{Resumen}

El conflicto armado interno en Colombia ha causado el desplazamiento forzado de millones de víctimas hacia las principales ciudades del país, entre 2017 y 2014, afectando las dinámicas de los mercados laborales. A partir del estudio de las dinámicas de la migración forzada -medida a través de pruebas de diferencia de medias y de los índices de presión y expulsión, y una revisión argumentativa literaria de la migración forzada y la migración económica- el trabajo analiza la integración de los desplazados en los mercados laborales de las 23 ciudades principales del país y describe sus posibles efectos laborales. Se muestra que los desplazados fallan en su integración económica como consecuencia de los obstáculos adicionales que enfrentan para trabajar. Además, que la estimación de los efectos de esta integración aún es ambigua debido a problemas metodológicos.

Palabras clave: migración regional; mercado de trabajo; ciudades colombianas; desplazamiento forzado.

\section{Abstract}

The internal armed conflict in Colombia has caused the forced displacement of millions of victims to the main cities of the country, affecting the dynamics of labor markets. From the study of the dynamics of forced migration in the country, measured through means difference tests, pressure and intensity indicators, and a literary review of forced and economic migration, the work analyzes the integration of the displaced in the labor markets in the 23 main cities of the country and describes its possible labor effects. It shows that displaced people fail in their economic integration as a result of the additional obstacles they face to work. In addition, the estimation of the effects of this integration is still ambiguous due to methodological problems.

Keywords: Regional Migration; Regional Labour Markets; Developing Countries; Displaced Person. 


\section{Introducción}

Colombia es un país en guerra, caracterizado por la desproporcionada agresión a los civiles. El desplazamiento forzado es el principal flagelo de este conflicto. Las cifras muestran que más del $87 \%$ de las víctimas son, por lo menos, desplazados forzados (RNI, 2016). Tras ser obligados a abandonar sus hogares, la mayoría de los desplazados encuentran refugio en las principales ciudades del país. Sin embargo, una vez allí encuentran enormes dificultades para acceder al mercado laboral que los margina y condena a una situación incluso peor a la de los pobres urbanos.

De igual forma, la presencia de los desplazados forzados en las ciudades del país tiene diversas consecuencias demográficas, sociales y económicas. En lo económico, el arribo de los desplazados a estas urbes afecta en especial al mercado laboral, que sufre un choque externo en su oferta. Lo que a la vez distorsiona algunas variables claves, como la participación laboral y el subempleo. Sin embargo, los efectos empíricos cuantitativos de los desplazados en las ciudades de Colombia aún son ambiguos, por lo que se requiere mayor investigación. En este sentido, han sido pocas las investigaciones que han estudiado los efectos del desplazamiento en los mercados laborales del país (ver Tabla 1).

Esta escasez de este tipo de estudios en el país no es diferente a la existente en la ciencia económica, donde los estudios sobre los efectos del desplazamiento han sido pocos (Bonilla, 2004; Egea y Soledad, 2008; Kuhlman, 2000). Esto debido, en primer lugar, a que en el campo de la economía sigue siendo dominante la visión que ve al desplazamiento forzado como un problema político y, por lo tanto, fuera del alcance como objeto de estudio. En segundo, porque la mayoría de las investigaciones sobre este fenómeno en Colombia plantean sus metodologías analíticas desde la perspectiva de las regiones en donde se presentan las expulsiones, dejando de lado lo que pasa en el lugar de recepción. Y como tercero, debido a la escasez de datos relevantes sobre el fe- nómeno, necesarios para estimar los efectos cuantitativos. ${ }^{5}$

Teniendo en cuenta la escasez y las dificultades de las investigaciones sobre los efectos del desplazamiento en el país, este trabajo aporta al estudio del fenómeno del desplazamiento forzado interno en Colombia. Específicamente, en la integración laboral de los desplazados y un análisis de los estudios sobre los efectos en los mercados laborales urbanos. Con este fin, el trabajo se concentra en el estudio de los efectos del desplazamiento en las 23 ciudades más grandes del país y sus áreas metropolitanas durante el periodo 2007-2014. De igual forma, se usan datos sobre el desplazamiento forzado en el país de los últimos 30 años del Registro Único de Víctimas (RUV), de la Red Nacional de Información (RNI) y datos de la Gran Encuesta de Hogares (GEIH) del Departamento Administrativo Nacional de Estadísticas (DANE), del periodo 2007-2014.

Para el análisis de la relación entre desplazamiento forzado y mercado laboral, se hace uso de una serie de cálculos del primer fenómeno y se combina con datos de las principales variables macroeconómicas del segundo. Entre los cálculos del desplazamiento forzado está la prueba $t$ de diferencia de medias, que sirve para constatar si el desplazamiento forzado ha causado desplazamientos poblacionales intradepartamentales en el país, y se calcula usando la media de personas expulsadas y la media de personas recibidas en cada departamento para el período estudiado. También se calculan los índices de presión y de expulsión ${ }^{6}$, que sirven para calcular cuáles son las ciudades más afectadas por este fenómeno. Del mercado laboral se utilizan variables como las tasas de ocupación (TO), la

5 Aunque, con respecto a este último punto, hay avances importantes gracias al esfuerzo de organizaciones como la Cruz Roja, la Red de Solidaridad Social, la Agencia de la ONU para los Refugiados (ACNUR), la Conferencia Episcopal a través del Secretario Nacional de Pastoral Social y la Consultoría para los Derechos Humanos y el Desplazamiento (CODHES) (Restrepo y Sadinle, 2009).

6 Índice de presión: número de personas desplazadas que llegan a una ciudad en un determinado período de tiempo por cada mil habitantes. Índice de expulsión: número de personas desplazadas por cada mil habitantes. 
Tabla 1. Colombia: estudios previos relevantes sobre la integración laboral y los efectos de los desplazados en los mercados laborales

\begin{tabular}{|c|c|c|c|}
\hline Autor & Metodología & Conclusiones & Enfoque \\
\hline $\begin{array}{l}\text { Lozano- Gracia, } \\
\text { Piras, Ibáñez y } \\
\text { Hewings (2009) }\end{array}$ & $\begin{array}{l}\text { Modelo espacial econométrico empíri- } \\
\text { co, como extensión del modelo } \\
\text { gravitacional migratorio tradicional. }\end{array}$ & $\begin{array}{l}\text { La violencia, la ausencia de la presencia } \\
\text { institucional y la insatisfacción con las } \\
\text { necesidades básicas son las causas más } \\
\text { relevantes del desplazamiento. }\end{array}$ & $\begin{array}{l}\text { Causas del } \\
\text { desplazamien- } \\
\text { to y comporta- } \\
\text { miento de los } \\
\text { desplazados. }\end{array}$ \\
\hline $\begin{array}{l}\text { Calderón y } \\
\text { Ibáñez (2009) }\end{array}$ & $\begin{array}{l}\text { Modelo econométrico con variables } \\
\text { instrumentales. }\end{array}$ & $\begin{array}{l}\text { Los flujos de desplazados reducen } \\
\text { sustancialmente los salarios urbanos de } \\
\text { los trabajadores no calificados. }\end{array}$ & $\begin{array}{l}\text { Efectos de los } \\
\text { desplazados en } \\
\text { los mercados } \\
\text { laborales. }\end{array}$ \\
\hline $\begin{array}{l}\text { Ibáñez y } \\
\text { Velásquez } \\
\text { (2008) }\end{array}$ & $\begin{array}{l}\text { Análisis estadístico de las condiciones } \\
\text { socioeconómicas de la población } \\
\text { desplazada }\end{array}$ & $\begin{array}{l}\text { Los desplazados tienen varias dificulta- } \\
\text { des en su inserción al mercado laboral: } \\
\text { habilidades no demandadas, bajo nivel } \\
\text { educativo, falta de documentos y } \\
\text { discriminación. }\end{array}$ & $\begin{array}{l}\text { Integración } \\
\text { laboral de los } \\
\text { desplazados. }\end{array}$ \\
\hline $\begin{array}{l}\text { Silva y } \\
\text { Sarmiento } \\
(2013)\end{array}$ & $\begin{array}{l}\text { Estimación de un modelo logístico } \\
\text { multinomial a partir de una submuestra } \\
\text { por sexo del Censo General del año } \\
2005 .\end{array}$ & $\begin{array}{l}\text { Los desplazados presentan una menor } \\
\text { tasa de participación laboral, como } \\
\text { consecuencia de su perfil socio-de- } \\
\text { mográfico. }\end{array}$ & $\begin{array}{l}\text { Integración } \\
\text { laboral de los } \\
\text { desplazados. }\end{array}$ \\
\hline Romero (2013) & $\begin{array}{l}\text { Estimación de un modelo de selección } \\
\text { múltiple ordenado usando datos de la } \\
\text { Encuesta de Calidad de Vida (ECV) del } \\
\text { DANE para } 2011 .\end{array}$ & $\begin{array}{l}\text { Ser migrante forzado incide negativa- } \\
\text { mente en la probabilidad de encontrarse } \\
\text { ocupado en el sector formal y positiva- } \\
\text { mente en la probabilidad de trabajar en } \\
\text { el sector informal o en estar desemplea- } \\
\text { do. }\end{array}$ & $\begin{array}{l}\text { Integración } \\
\text { laboral de los } \\
\text { desplazados. }\end{array}$ \\
\hline Flórez (2003) & $\begin{array}{l}\text { Estimación del perfil de los migrantes } \\
\text { en las } 10 \text { principales ciudades de } \\
\text { Colombia, a partir de información de la } \\
\text { Encuesta Nacional de Hogares de 1984, } \\
1992 \text { y } 2000 \text {. }\end{array}$ & $\begin{array}{l}\text { Los desplazados tienen una mayor tasa } \\
\text { de participación laboral, pero menos } \\
\text { capital humano que los nativos. }\end{array}$ & $\begin{array}{l}\text { Integración } \\
\text { laboral de los } \\
\text { desplazados }\end{array}$ \\
\hline
\end{tabular}

general de participación (TGP) y la de subempleo (TS), entre otras. Relaciones que se utilizan para explicar la concentración de los desplazados en las grandes ciudades y los efectos -en magnitud, extensión y duración- que tienen estas dinámicas en las principales variables del mercado laboral.

Para esto, se presenta en la primera sección un marco teórico sobre el estudio de las migraciones desde la ciencia económica, la relación entre la migración forzada y la migración voluntaria o económica, y los efectos teóricos de la migración en los mercados laborales. En la segunda, se muestran las generalidades del desplazamiento, sus macro características relativas al territorio, la migración campo-ciudad, y la concentración y presión poblacional del desplazamiento en las ciudades; también, en esta sección, se presenta una caracterización de la población desplazada. En la tercera, se analiza la integración laboral de los desplazados en el mercado laboral de las ciudades, comparándolos con la de los migrantes económicos; y después se teoriza sobre los estudios y posibles efectos de los desplazados en los mercados laborales. Finalmente, se concluye.

\section{Aproximación teórica a la relación migración-economía}

\subsection{Teoría económica de la migración}

El concepto de migración es usado con muchas acepciones, tanto en la academia como en el 
lenguaje cotidiano. Puede ser vista como un fenómeno temporal o permanente, transnacional o nacional, individual o grupal, forzado o voluntario, entre otras clasificaciones. Por esto es necesario usar criterios de tiempo y espacio para precisar el concepto (Poulain y Perrin, 2001). De igual forma, el tipo de análisis y volumen de los datos disponibles dependen del tipo de migración que se estudie, pero no hay antecedentes bibliográficos que indiquen que los hallazgos teóricos no sean de común aplicación (Herrera, 2006). Es decir, la teoría económica sobre los migrantes económicos o voluntarios también aplica para los migrantes forzados.

Los estudios sobre la migración se han caracterizado por ser un campo interdisciplinario, en donde se consolidan aportes de la antropología, la historia, el derecho, la economía y la ciencia política, entre otras. Debido a esto, las teorías sobre la migración están fragmentadas, lo que dificulta reunir y organizar las diferentes propuestas realizadas en una teoría general de la migración. Específicamente en economía, el estudio de este fenómeno ha evolucionado en paralelo a las principales corrientes teóricas de la disciplina (Lucas, 1997). Actualmente no existe una única aproximación aceptada a la migración, sino un conjunto de teorías fragmentadas y desarrolladas al margen unas de otras.

Inicialmente las teorías económicas han explicado a la migración como función de la distancia y el volumen de los centros poblacionales. Ernst Georg Ravenstein (1885) formuló las leyes de la migración, en donde deja entrever la noción del llamado del trabajo de los centros de industria y comercio como el causante de las corrientes migratorias. Por encima de cuestiones políticas, es el motivo económico el origen de la mayoría de las migraciones. Estas leyes, si bien han sido acusadas de ser simples generalizaciones (Forman, 1975), en la actualidad, son un punto de referencia en cualquier estudio sobre migración. De forma similar, los modelos de gravedad de la migración (Gravity Models) relacionan el volumen de la migración positivamente con el tamaño de los lugares de origen y destino, y negativamente con la distancia entre ellos (Stouffer, 1940; Zipf, 1946). Explican la mi- gración por el principio del menor esfuerzo: el lugar más grande y cercano será el elegido por el migrante.

Igualmente, es relevante la teoría migratoria económica de los factores de empuje y atracción, conceptualizada por Lee (1966). El trabajo de este autor plantea la existencia de variables atrayentes o repelentes, asociadas tanto al área de origen como de destino, que influencian las decisiones migratorias individuales. Estos elementos pueden afectar a toda la población de la misma forma -clima poco atractivo- o afectar de forma distinta a cada individuo: calidad de la educación básica. Adicionales a estos factores, existen obstáculos a la migración, leves en algunos casos e insuperables en otros, que afectan diferente a cada individuo. Lo que para algunos puede ser trivial -costo de mudanza- para otros puede llegar a ser prohibitivo. De esta forma, los factores de atracción y repulsión, y las barreras a la migración afectan tanto el volumen migratorio como las características de los migrantes.

Desarrollos adicionales explican las migraciones desde las diferencias en los ingresos, el empleo y las comodidades. Por ejemplo, Todaro (1969) explica las migraciones como respuesta a las diferencias esperadas de los salarios y las tasas de desempleo entre las zonas urbanas y rurales. Lucas (1997) plantea que, a medida que se expande el sector industrial y de servicios en relación al agrícola, la migración del campo a la ciudad surge como una estrategia para el desarrollo y la creación de empleo. Mientras que Ackah y Medvedev (2010) conciben a la migración como consecuencia de la búsqueda de mejores comodidades, como acceso a hospitales, agua potable y alcantarillado. Estas y otras teorías sobre el estudio de la migración se pueden agrupar en tres enfoques básicos: macro-económico, microeconómico y meso-económico (ver Tabla 2).

\subsection{Teoría de la migración y el desplazamiento forzado}

La literatura económica sobre la etiología de los flujos de migrantes forzados ha sido relativamente pequeña, en comparación con la literatura sobre la migración impulsada por incenti- 
Desplazamiento forzado y mercado laboral en las principales ciudades de Colombia

\begin{tabular}{|c|c|c|c|c|}
\hline $\begin{array}{l}\text { Enfoque } \\
\text { económico }\end{array}$ & $\begin{array}{c}\text { Características } \\
\text { principales }\end{array}$ & Elementos de estudio & Elementos de estudio & Referencias \\
\hline $\begin{array}{l}\text { Macro- } \\
\text { económico }\end{array}$ & $\begin{array}{l}\text {-La migración mejora la } \\
\text { eficiencia y equilibra } \\
\text { los mercados laborales } \\
\text { regionales. } \\
\text {-Supone pleno empleo } \\
\text { y competencia perfecta. }\end{array}$ & $\begin{array}{l}\text {-Situación económica, } \\
\text { política y demográfica } \\
\text { de la región. } \\
\text {-Mercados laborales. } \\
\text {-Leyes, regulaciones y } \\
\text { ciclos económicos. }\end{array}$ & $\begin{array}{l}\text {-Oportunidades a nivel } \\
\text { macroeconómico. } \\
\text {-Diferencias geográficas } \\
\text { en el ingreso y en la } \\
\text { oferta o demanda de } \\
\text { trabajo. }\end{array}$ & $\begin{array}{l}\text {-Devillanova y García } \\
\text { (1998). } \\
\text {-Massey et al. (1993). } \\
\text {-Todaro (1969). }\end{array}$ \\
\hline $\begin{array}{l}\text { Micro- } \\
\text { económico }\end{array}$ & $\begin{array}{l}\text {-Los individuos eligen } \\
\text { desplazarse a donde } \\
\text { son más productivos. } \\
\text {-La migración es una } \\
\text { forma de inversión en } \\
\text { capital humano. }\end{array}$ & $\begin{array}{l}\text {-Deseos y expectativas } \\
\text { de los individuos. } \\
\text {-Capital humano. } \\
\text {-Costos de la migración. }\end{array}$ & $\begin{array}{l}\text {-Comparaciones } \\
\text { individuales de } \\
\text { costo-beneficio entre } \\
\text { los rendimientos } \\
\text { esperados en el lugar de } \\
\text { destino y de origen. }\end{array}$ & $\begin{array}{l}\text { - Becker (1975). } \\
\text { - Sjaastad (1962). } \\
\text { - Todaro (1969). }\end{array}$ \\
\hline $\begin{array}{l}\text { Meso- } \\
\text { económico }\end{array}$ & $\begin{array}{l}\text {-Los migrantes } \\
\text { consideran incentivos } \\
\text { asociados al mercado } \\
\text { de futuros y seguros. } \\
\text {-Las familias relocalizan } \\
\text { sus recursos humanos } \\
\text { en diferentes lugares } \\
\text { geográficos para } \\
\text { diversificar los riesgos. }\end{array}$ & $\begin{array}{l}\text { - Familias en vez de } \\
\text { individuos. } \\
\text {-Lazos colectivos y } \\
\text { sociales entre los } \\
\text { individuos y su } \\
\text { comunidad. }\end{array}$ & $\begin{array}{l}\text {-Maximización de la } \\
\text { utilidad y minimi- } \\
\text { zación de los riesgos } \\
\text { colectivos. } \\
\text {-Lazos sociales en las } \\
\text { sociedades receptoras. }\end{array}$ & $\begin{array}{l}\text { - Arango (2003). } \\
\text { - Herrera (2006). } \\
\text { - Massey et al. (1993). } \\
\text { - OIM (2001). }\end{array}$ \\
\hline
\end{tabular}

Fuente: elaboración propia.

vos económicos (Bonilla, 2004; Egea y Soledad, 2008). En este sentido, Kuhlman (2000) afirma:

En el campo de la migración forzada; sin embargo, la investigación económica es extremadamente escasa. Es válido suponer que los economistas tienden a considerar a la migración involuntaria como un elemento fuera de su dominio, pues es causada por factores políticos arbitrarios y no por las fuerzas del mercado (p. 1, traducción propia).

La ausencia de estudios académicos sobre el tema se ha dado principalmente por dos razones: primero, la percepción del desplazamiento forzado como un problema político en vez de económico, causado por factores políticos arbitrarios y no la interacción de fuerzas de mercado (Lucas, 1997, p. 755); y segundo, la creencia de que la relación entre la migración forzada y su causa violenta es simplista, y menos compleja que la existente entre migración voluntaria y las condiciones económicas (Davenport, Moore y Poe, 2003; Massey et al., 1993). No obstante, existen importantes aportes desde la teoría económica sobre la migración forzada.
En economía, la visión más extendida entiende a las migraciones ocasionadas por conflictos armados como similares a las causadas por los desastres naturales. Se considera que ambas impactan aleatoriamente a las comunidades, como si fueran un experimento natural. Por lo que las personas no eligen migrar por sí mismas, sino que son elegidas por el conflicto de forma aleatoria (Clifford, 1970; Lozano-Gracia et al., 2010). Además, se cree que los individuos solo pueden lidiar con un problema mayor a la vez, por lo que no consideran las implicaciones de su desplazamiento (Stark, 1991). De esta forma, los diferentes niveles de amenaza que perciben los individuos, mas no la comparación de la utilidad esperada de su migración, originan los procesos migratorios (Guataquí, 2006).

Sin embargo, en los últimos años, este paradigma ha empezado a cambiar. Investigaciones recientes sugieren que la migración forzada también es selectiva, de forma similar a la migración económica. Ante la violencia y otros factores de expulsión no todas las familias migran, por lo que desplazarse es solo una de las posibles 
estrategias de supervivencia (Justino, 2012). Así, las familias toman la decisión de migrar no solo basadas en el riesgo de ser víctimas del conflicto, sino también en los incentivos económicos. De esta forma, si los individuos deciden desplazarse, lo harán hacia un lugar que satisfaga sus necesidades económicas y de seguridad. $\mathrm{Al}$ respecto, Engel e Ibáñez (2007) afirman:

\begin{abstract}
Al momento de tomar la decisión de si dejar o permanecer en sus hogares, las familias deben considerar los riesgos y beneficios potenciales de las dos opciones y elegir la mejor para ellos. O quizás, más apropiadamente, elegir el menor de los males (p. 338, traducción propia).
\end{abstract}

Asimismo, nuevas teorías plantean como simplista la clasificación de los migrantes como voluntarios o forzados. Los conflictos pueden causar una devastación económica tal que induzca a la gente a buscar mejores condiciones y a convertirse en refugiados económicos, sin que sean expulsados explícitamente por la violencia (Blanco, 2000; Sales, 2007). Además, los hogares no solo deben decidir si se desplazan o no, sino también qué miembros de la familia lo van a hacer. Es posible que algunos miembros de la familia migren para crear las condiciones mínimas de subsistencia para el resto, mientras que otros se queden y continúen extrayendo rentas de sus tierras (Ibáñez y Velásquez, 2008, p. 63). Estas nuevas visiones, aunque sean esfuerzos esporádicos, han acortado la distancia teórica entre las migraciones forzadas y económicas.

\subsection{Efectos teóricos de la migración en los mercados laborales}

Los principales afectados por la migración son los propios migrantes, quienes después de desplazarse e incurrir en costos adicionales deben enfrentar un proceso de asimilación necesario para su adaptación y aculturación. Son ellos los que deben encarar nuevos desafíos, como un lenguaje y costumbres diferentes, y el aprendizaje de los conocimientos necesarios sobre la naturaleza de los trabajos requeridos (Herrera, 2006). Estas nuevas condiciones determinan la correcta integración socioeconómica de los inmigrantes en la sociedad que los recibe.

En este sentido, por un lado, los migrantes que logran una integración económica exitosa suelen tener mayores tasas de participación laboral y menores tasas de desempleo en comparación a la población nativa (Silva y Guataquí, 2008). Además, en el largo plazo incrementan sus ingresos, incluso hasta niveles iguales o superiores a los de los nativos (Chiswick, 1978). Por otro, los migrantes que fallan en su integración caen en una posición desventajosa; se ven forzados a trabajar en empleos mal pagos -usualmente del sector informal-, o a caer en el desempleo y en trampas de pobreza (Romero, 2013). En últimas, son percibidos como una carga o problema sociopolítico y son marginados (Herrera, 2006).

A partir de la integración de los migrantes, surgen efectos económicos en el mercado laboral que dependen tanto de las características de la economía receptora como de los recursos con los que cuentan nativos e inmigrantes (calificación profesional, redes sociales, habilidades personales, acompañamiento estatal, etc.). Además, como es de esperarse, la magnitud de estos efectos depende del volumen relativo de los flujos migratorios; es decir, de la proporción poblacional que alcancen los inmigrantes en la localidad de recepción (Altonji y Card, 1991; Borjas, 1994). Por esto, los hallazgos empíricos sobre los efectos de la migración siempre son específicos a un lugar y un tiempo (CONAPO, 2010; Ruhs y Vargas, 2015).

Varias investigaciones -como la de Lalonde y Topel (1991), Borjas, Freeman y Katz (1997), Grossman (1982) y Ruhs y Vargas (2015), a partir del modelo básico del mercado de trabajo con diferenciación de las habilidades de los trabajadores- han analizado los efectos a corto plazo de la inmigración de individuos poco calificados. Encontraron que la llegada de estos inmigrantes afectó la distribución de los ingresos en la urbe receptora. Por un lado, disminuyó los salarios de inmigrantes pasados y de trabajadores nativos con capacidades similares -sus substitutos cercanos- sin tener consecuencias apreciables en las oportunidades 
de empleo de estos; por otro, incrementó los ingresos de los trabajadores más calificados y de los dueños de capital, como consecuencia de una disminución relativa del precio del trabajo poco calificado.

Estos resultados pueden ser modificados por otros factores propios del mercado laboral. En mercados laborales, con curvas de oferta laboral elásticas, la inmigración de trabajadores poco calificados puede crear desempleo voluntario entre los nativos con habilidades similares (Dustmann, Glitz y Frattini, 2008). De igual forma, los costos de transacción, como la falta de documentación personal -libreta militar, pasaporte, cédula, etc.-, el idioma o la cultura, pueden segmentar el mercado laboral y crear barreras que limitan la integración de los inmigrantes al mercado laboral formal (Casasfranco, 2002, p. 111). Finalmente, si los salarios de la economía son iguales al salario mínimo, un exceso de oferta laboral puede obligar a algunos individuos a trabajar en el sector informal (Calderón e Ibáñez, 2009).

Más allá de los factores que modifican los efectos de la migración en el lugar de destino, existen dificultades metodológicas que pueden comprometer la efectividad de estos estudios. Estas investigaciones están basadas en la auto-correlación espacial, es decir, explican las variables dependientes del mercado laboral en una unidad geográfica, parcialmente en función de la concentración de migrantes que existe. Evocando con ello la Primera Ley de la Geografía de Tobler (1970) que afirma: "Todo está relacionado con todo lo demás, pero las cosas cercanas están más relacionadas que las distantes" (p. 234, traducción propia).

Sin embargo, esta aproximación tiene dos grandes problemas (Borjas, 2003; Dustmann et al., 2008). En primer lugar, como se discutió antes, los migrantes no se distribuyen en distintas áreas geográficas de forma aleatoria, sino que eligen su destino basados en sus expectativas laborales y otros factores. De esta forma, los migrantes suelen ir hacia ciudades donde el aumento en la demanda se acomode a su oferta de trabajo (Borjas et al., 1997; Card, 1990; Dustmann et al., 2008). De allí que, si las expectativas salariales de los migrantes son correctas y la región a la que piensan desplazarse es efectivamente la que tiene el mayor incremento salarial, las estimaciones de los efectos de la migración en estos lugares serían positivas. Lo que sugeriría que la migración incrementa los salarios aun cuando en realidad su efecto sea nulo o negativo, en cuyo caso los efectos de la migración serían contrarrestados por otros factores.

En segundo lugar, el otro gran problema de este tipo de estudios es la capacidad de ajuste de los mercados laborales regionales frente la migración. Ante fenómenos migratorios, los nativos y otras cohortes de migrantes pueden modificar sus decisiones migratorias. Lo que disipa los efectos de los migrantes por toda la región y opaca las correlaciones espaciales entre los salarios, el nivel de empleo y los flujos de migrantes (Borjas et al., 1997; Dustmann et al., 2008; Walker, Ellis y Barff, 1992). Por ejemplo, los nativos pueden ser disuadidos de emigrar hacia un sitio con un flujo actual de inmigrantes al ver que sus potenciales salarios en ese lugar se han reducido. También, de forma contraria, pueden considerar emigrar si ven sus actuales oportunidades laborales comprometidas.

\section{Dinámica del desplazamiento forzado en Colombia}

\subsection{Relación campo-ciudad del desplazamiento forzado}

A enero primero de 2016, se encuentran registradas como desplazadas, en el Registro Único de Victimas (RUV), 6.646.395 personas (RNI, 2016). Esta cifra abarca el periodo $1985-2015$ y es acumulativa, por lo que no resta a los desplazados que han logrado una solución duradera, o los que nacieron o murieron durante el desplazamiento. Estas personas equivalen al $13,7 \%$ de la población de Colombia y lo ubican como el segundo país con más desplazados internos en el mundo, detrás de Siria (IDMC, 2016). Si bien el volumen de víctimas que muestran las cifras es considerable, existe un sub-registro en 
la cuantificación de los desplazados por parte de las organizaciones gubernamentales, como consecuencia de la falta de información o documentación, miedo, hostigamiento, detención, posible devolución o rechazo, entre otros.

Las cifras muestran que el desplazamiento es casi en su totalidad interno: solo el 5,62\% de los migrantes forzados se convierten en refugiados en otros países (UNHCR, 2015). Las víctimas no son forzadas a abandonar el país, sino que se convierten en apátridas en su propia nación (Uribe, 2002). Al momento de migrar, los desplazados cuentan con diversas opciones de destino dentro del país, que son suficientes para poner a salvo su vida: el $76 \%$ de los desplazados no han sido re-victimizados (RNI, 2016). Esto gracias a la diversidad de las zonas geográficas y las características sociales, a las fragmentaciones regionales y la distribución del control de las áreas entre los distintos grupos armados. Además, los desplazamientos suelen ser de corta distancia. El $63 \%$ de los desplazados se moviliza a la cabecera municipal más cercana, usualmente dentro de su mismo departamento de expulsión (Ibáñez y Velásquez, 2008).

En Colombia, ningún departamento está al margen del desplazamiento: todos han experimentado en mayor o menor medida la expulsión de su población. De hecho, el $99 \%$ de los municipios que conforman el territorio nacional han registrado al menos una víctima del desplazamiento forzado (CNMH, 2015). Según cifras de la RNI, durante los últimos 30 años, en siete departamentos el nivel de población no se vio afectado por el desplazamiento, en 15 de ellos disminuyó y en 11 aumentó?. Lo que significa que no existen movimientos poblacionales evidentes de gran escala de un departamento a otro como consecuencia del desplazamiento.

En cambio, las estadísticas muestran una importante relación entre las ciudades y el campo. Las ciudades son grandes receptoras de la po-

7 Cálculos de los autores basados en una prueba t de diferencia de medias. Siendo, la media de personas expulsadas en un departamento dado y, la media de personas recibidas (ver Anexo A). blación desplazada. Las urbes qué más desplazados forzados recibieron durante el periodo 2007-2014, en el país, fueron Bogotá (229.314), Medellín (175.537) y Cali-Yumbo (69.444); centros urbanos que atraen a gran cantidad de migrantes forzados o no, gracias a su concentración poblacional ${ }^{8}$ y las oportunidades económicas que ofrecen (Galvis, 2002). Aunque hay otras ciudades como Santa Marta (67.171), Popayán (63.089) y Florencia (48.035), que si bien no concentran tanta población ${ }^{9}$, sí atraen a muchos desplazados (ver Gráfico 1).

Las ciudades capitales del país reciben un volumen de desplazados forzados congruente con la proporción de población departamental que albergan, pero expulsan menos. En este sentido, entre 2007 y 2014, las 23 ciudades principales de Colombia ${ }^{10}$ recibieron, en promedio, el $43,45 \%$ de los desplazados acogidos en su respectivo departamento y expulsaron al $12,59 \%$. Mientras que la población de estas urbes representó, en promedio, el $43,52 \%$ de la población de su respectivo departamento. Esta dinámica dispar, entre las ciudades y los departamentos, causa una concentración de migrantes forzados en las urbes: llegan más migrantes forzados a las ciudades de los que son expulsados.

La llegada de los desplazados a las ciudades implica una presión demográfica en estos sitios, lo que a su vez determina la magnitud de los efectos económicos que tienen en ellos. Se debe considerar, entonces, cuántos desplazados llegan a una urbe de forma relativa y no absoluta. En este sentido, los índices de presión e intensidad son útiles. El índice de presión calcula el

8 Población de 2014 basada en estimaciones del Censo de 2005: Bogotá (7.776.845), Medellín (3.682.484) y Cali (2.459.161).

9 Población de 2014 basada en estimaciones el Censo de 2005: Santa Marta (476.385), Popayán (275.129) y Florencia (169.336).

10 Ciudades consideradas: 1. Bogotá, 2. Medellín, 3. Cali-Yumbo, 4. Barranquilla-Soledad, 5. Bucaramanga, 6. Manizales y Villamaría, 7. Pasto, 8. Pereira, 9. Cúcuta, 10. Ibagué, 11. Montería, 12. Cartagena, 13. Villavicencio, 14. Tunja, 15. Florencia, 16. Popayán, 17. Valledupar, 18. Quibdó, 19. Neiva, 20. Riohacha, 21. Santa Marta, 22. Armenia, 23. Sincelejo. 


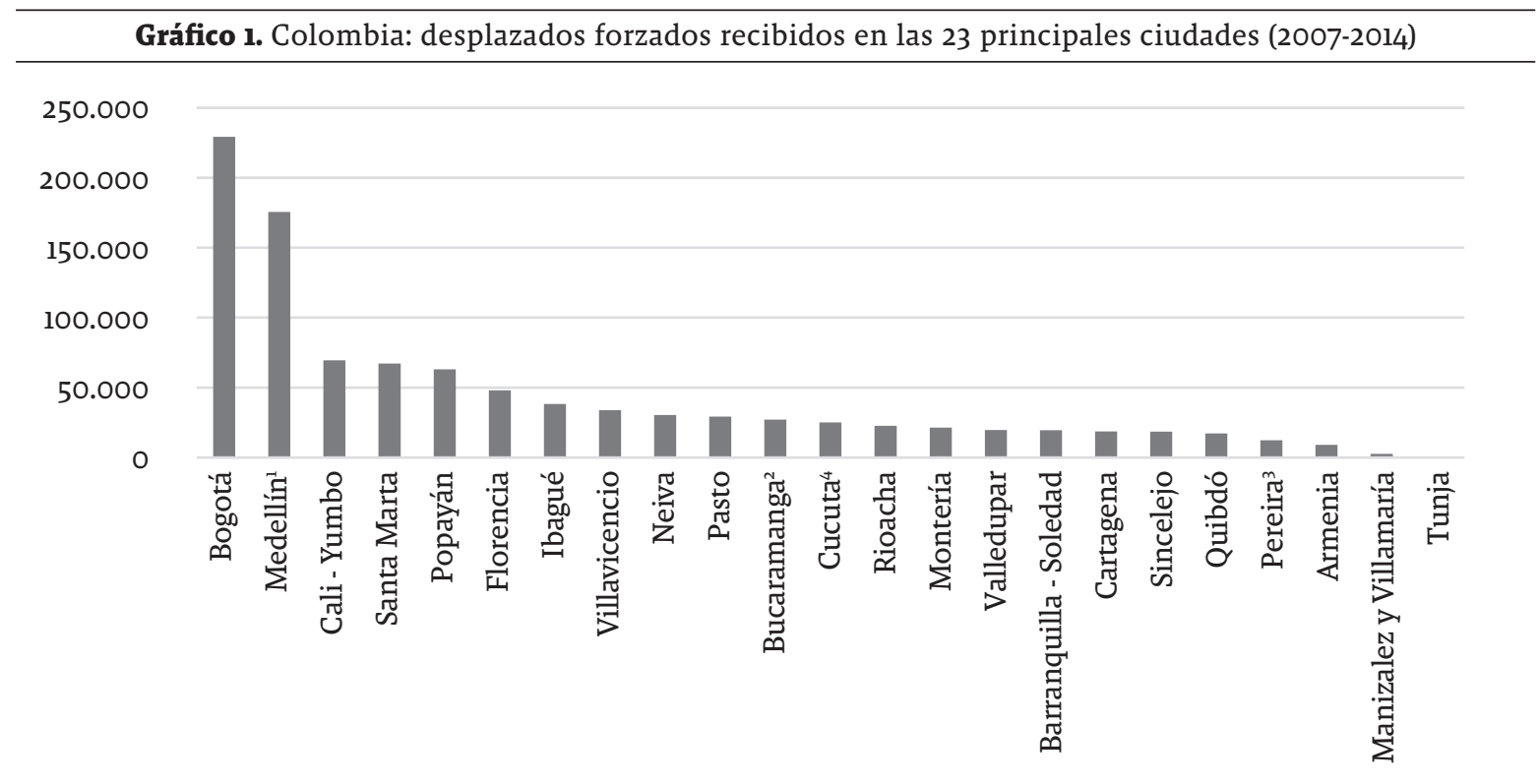

Notas: ${ }^{1}$ Área Metropolitana de Medellín, ${ }^{2}$ Bucaramanga, Girón, Piedecuesta y Floridablanca, ${ }^{3}$ Pereira, Dos Quebradas y La Virginia, y ${ }^{4}$ Cúcuta, Villa del Rosario, Los Patios y El Zulia.

Fuente: elaboración propia con datos del DANE.

número de desplazados que llegan a una ciudad en un determinado periodo de tiempo, por cada mil habitantes, mientras que el índice de expulsión calcula el número de personas expulsadas por cada mil habitantes. Estas medidas varían a través del país y dependen de las dinámicas propias del conflicto. Como se observa (ver Gráfico 2) los índices de presión y de expulsión están correlacionados. Las ciudades con mayor índice de presión también son las que tienen un mayor índice de expulsión.

Las ciudades grandes (con más de un millón de habitantes) -si bien en términos absolutos son las que reciben mayores flujos de desplazados- no son presionadas, puesto que la población desplazada que reciben en relación a su población total es baja. Por ejemplo, durante el periodo 2007-2014, la ciudad de Bogotá recibió 30 desplazados por cada 1000 hab.; Medellín, 47; Cali, 28; Barranquilla, 11; y Bucaramanga, 24. En cambio, la situación de algunas ciudades inter-

sociedad y economía No. 37, 2019•pp. 50-70 medias $^{\text {Il }}$ es diferente: reciben a una gran cantidad de víctimas en relación a su población total. Es el caso de ciudades como Florencia, que durante el mismo periodo recibió 280 desplazados por cada 1000 hab.; Popayán, 229; Quibdó, 149; y Santa Marta, 141. Debido a que son las ciudades intermedias las más presionadas por la llegada de los desplazados forzados, los posibles efectos del desplazamiento forzado en los mercados laborales serán más visibles allí.

\subsection{Características de la población desplazada}

El desplazamiento forzado no afecta de forma homogénea a la población del país. Son las personas en áreas rurales las más perjudicadas. La mayoría, el $87 \%$ de los desplazados, provienen de zonas rurales (CNMH, 2015; RNI, 2016). Así mismo, la estructura etaria de la población desplazada es diferente. Esta es, en promedio, un

11 Ciudades con más de cien mil y menos de un millón de habitantes. 
Gráfico 2. Colombia: índices de presión y de expulsión en las 23 principales ciudades, 2007-2014 (en escala logarítmica)

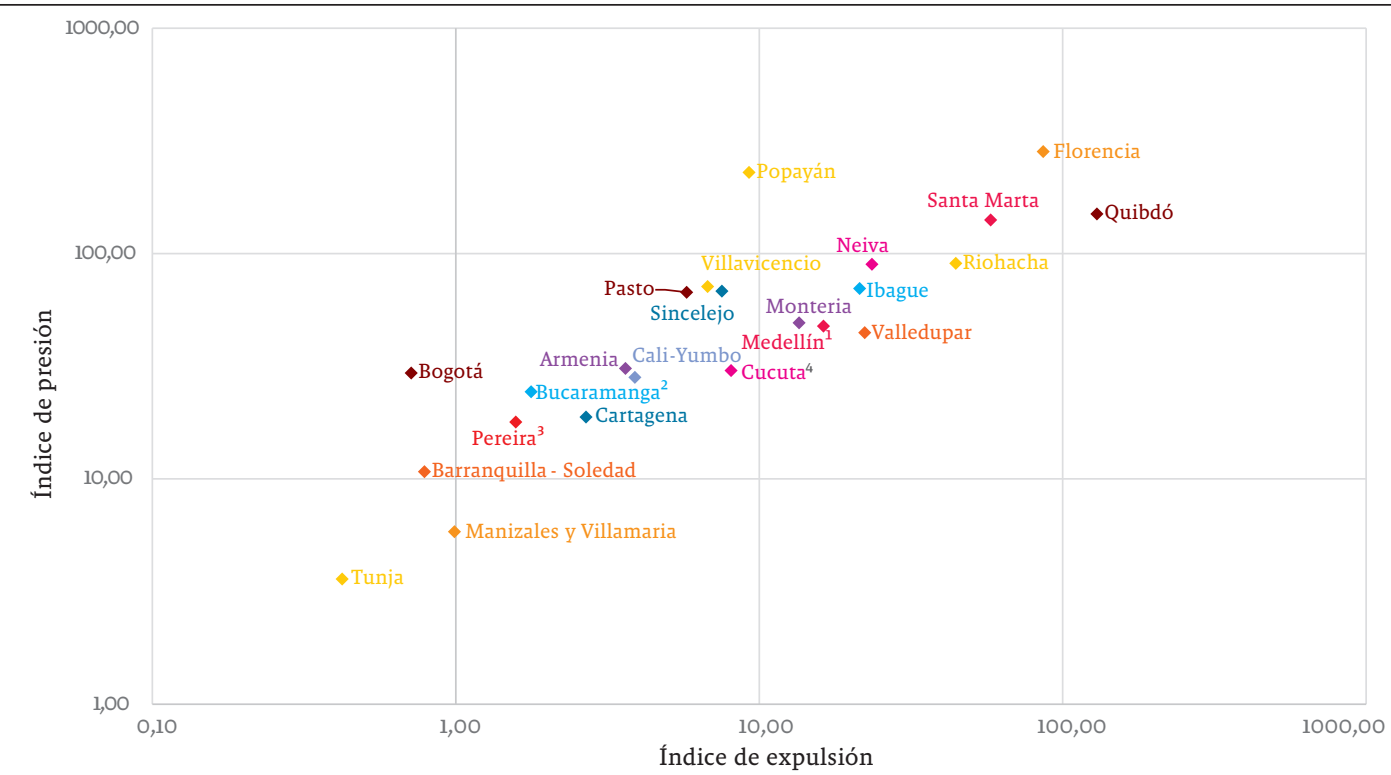

Fuente: elaboración propia con datos del DANE.

$13 \%$ más joven. Por lo que la población desplazada en edad para trabajar $(5.479 .572,92,09 \%)$ es mayor a la nacional: $81,58 \%$ (RNI, 2016). En cuanto a la composición de géneros, los desplazados son similares al resto de la población colombiana: de las 6.201.531 personas desplazadas entre 1985 y 2014, $51,07 \%$ son mujeres y $48,5 \%$, hombres. Sin embargo, cuando se comparan edad y género, se observan diferencias adicionales: entre los desplazados, los hombres predominan en la población dependiente (menores de 17 años y mayores de 60) y las mujeres, en la población económicamente activa.

Otro factor importante a considerar es la composición étnica de la población desplazada. Del total de personas expulsadas entre 1985 y 2014, según clasificación de Acción Social, el 13,12\% se auto-reconocen como minorías étnicas: $2,31 \%$ indígenas, $0,45 \%$ gitanos, $10,27 \%$ negros o afrocolombianos, y $0,1 \%$ raizal del archipiélago de San Andrés y Providencia (RNI, 2016). Estas minorías son más vulnerables debido al doble rechazo que deben enfrentar, por su condición de desplazados y de minoría étnica. No solo deben sufrir la violencia y el destierro, sino también sortear mayores desafíos a los vividos por otras víctimas, como cambios culturales o racismo.
Igualmente, otras características determinantes son el nivel de educación y las habilidades laborales de los desplazados. En este sentido, los desplazados enfrentan dos problemas. En primer lugar, las familias desplazadas tienen un nivel de educación, en promedio, inferior al colombiano: su tasa de analfabetismo es de poco más del $20 \%$, mientras que el promedio nacional es de $9,6 \%$. A la vez que tienen menos años de educación, el promedio de años de estudio del jefe de hogar y la cónyuge es de 5,7 (Ibáñez y Velásquez, 2008), mientras que en el país es de 7,7 años (DANE y UARIV, 2015). En segundo lugar, enfrentan una desvalorización o descualificación de sus habilidades agrícolas y pecuarias, ya que en las ciudades estos saberes no son demandados. $\mathrm{El} 57,95 \%$ de los desplazados trabajaba en labores agrícolas (Lozano-Gracia et al., 2010).

Aparte de las características de los desplazados, se deben tener en cuenta los perjuicios directos que enfrentan como consecuencia de la violencia. Por una parte, pierden su tierra que no alcanzan a vender o venden a precios muy bajos, y otros activos monetarios y físicos (Ibáñez y Velásquez, 2008). Además, enfrentan secuelas, en su salud mental, que pueden afectar su capacidad laboral. Sufren trastornos relacionados 
con el estrés postraumático como ansiedad, depresión severa y alcoholismo (Guerra y Juárez, 2011; Silva y Guataquí, 2008). Todo esto mientras pierden las garantías y el aseguramiento de sus derechos fundamentales (Gónzales y Mendoza, 2010). Factores que dificultan todavía más su integración a la sociedad que los recibe y en especial al mercado laboral.

\section{Integración de los desplazados en el mercado laboral}

\subsection{Integración de los desplazados forzados en los mercados laborales}

Las características del fenómeno migratorio en Colombia son muy particulares, aun cuando a nivel teórico el desplazamiento forzado y la migración económica comparten varias características como los cambios demográficos, la transición social y los cambios de estatus. En el país, el fenómeno estudiado conserva grandes diferencias, no solo, como es obvio, en las causas de la migración, sino también en las dinámicas del movimiento. La teoría, por ejemplo, sugiere que la migración es más rentable para los individuos más hábiles y altamente motivados, en respuesta a incentivos económicos, este tipo de migrante logra superar los obstáculos migratorios que detienen la migración de los menos capacitados (Chiswick, 1978; Lee, 1966). Sin embargo en Colombia con el desplazamiento forzado ocurre lo contrario: se obliga a migrar a personas altamente vulnerables y sin las habilidades necesarias para integrarse exitosamente al lugar al que se desplazan, además de despojarlos de su capital y redes sociales. Otra diferencia notable es que, mientras los migrantes voluntarios o económicos encuentran barreras u obstáculos al momento de desplazarse -como los costos de mudanza-, los desplazados, a pesar de la extensa violación de sus derechos, no hallan grandes barreras al momento de movilizarse por el país: las encuentran después de desplazarse, al intentar trabajar.

De esta forma, los desplazados enfrentan grandes dificultades al momento de acceder al mer- cado laboral, debido a sus condiciones socioeconómicas: bajo nivel educativo, poca experiencia laboral en los trabajos citadinos (Bernal, 2009; Flórez, 2003; Silva y Guataquí, 2008) y falta de capital económico (Restrepo y Sadinle, 2009). Otros, por la respuesta de la población en las ciudades: estigmatización, discriminación (Naranjo, 2004; Red Ormet, 2014) y trastornos mentales (Guerra y Juárez, 2011). Así también, por la exigencia de documentos como la cédula de identidad o la libreta militar (Ibáñez y Velásquez, 2008; Silva y Sarmiento, 2013). Solo el 35,9\% de los desplazados hombres, mayores de edad, cuentan con libreta militar (DANE y UARIV, 2015).

Estas dificultades implican un detrimento en la capacidad de los desplazados de generar ingresos y los pone en desventaja frente a la población nativa, a la hora de competir en el mercado laboral. Situación reflejada en sus tasas de desempleo, mayores que las del resto de la población: en 2012, la tasa de desempleo para la población desplazada fue de $35,5 \%$ y su tasa de ocupación, del $40 \%$, mientras que para el total nacional fue de $10,2 \%$ y $57 \%$, respectivamente (PNUD, 2014). Esto teniendo en cuenta que los desplazados tratan de evitar el desempleo, pues no tienen la capacidad de financiar la búsqueda de trabajo, ni tienen seguros de desempleo (Uribe, Ortiz y García, 2008).

Al no encontrar empleo, los desplazados se ven obligados a vincularse a trabajos de baja calidad en el sector informal. Cerca del 55\% de la población desplazada está vinculada al sector informal, cuando para el resto de la población dicha cifra es del 42\% (Ibáñez y Velásquez, 2008). Usualmente estos empleos se caracterizan por ser de ingresos inadecuados, baja productividad, con condiciones inadecuadas de trabajo y sin seguridad social. Muchos desplazados pasan de ser agricultores en su tierra a ser vendedores informales o pequeños comerciantes (Ibáñez y Querubín, 2004). Otros simplemente abandonan el proceso de búsqueda y dejan de ser parte de la fuerza laboral (Silva y Sarmiento, 2013). La tasa de participación laboral de los desplazados es un poco menor a la nacional: en el 2012 fue de $62 \%$, mientras que el total nacional fue de 64,5\% (Red Ormet, 2014). 
Su inhabilidad para integrarse de forma exitosa al mercado laboral los cerca en un panorama de escasa seguridad, y marginalidad económica y social. Enfrentan una situación económica incluso peor que la enfrentada por los pobres e indigentes de las ciudades. Mientras las tasas de pobreza y pobreza extrema para el total del país, en 2014 , fueron de $25 \%$ y $7,4 \%$, respectivamente, para los desplazados fueron de $63,9 \%$ y $33 \%$ (DANE y UARIV, 2015). Además, solo el 19,5\% de los hogares desplazados ocupan una vivienda en condiciones dignas. Incluso con el paso del tiempo y después de haber consolidado un asentamiento estable, los desplazados continúan atrapados en una trayectoria de bajo nivel económico (Ibáñez y Moya, 2010, p. 168). En este sentido, el desplazamiento forzado genera una trampa de pobreza para las víctimas.

Esta fallida integración económica también implica que, cuando ocurre un desplazamiento forzado, la fuerza laboral que se pierde en el campo no se gana en la ciudad, a diferencia de lo que ocurre con la migración voluntaria: hay un desplazamiento de la oferta laboral. La migración, en Colombia, en vez de ser un motor de desarrollo, como lo es en otras latitudes, es una trampa para las víctimas del conflicto armado. Los desplazados logran escapar de la violencia del campo, pero se encuentran con el hambre en las ciudades. Pasan de ser afectados de la guerra, a ser marginados y discriminados.

\subsection{Tasa de participación laboral de los desplazados forzados}

La teoría económica sugiere que la tasa global de participación laboral (TGP) depende de la comparación realizada por los individuos entre su salario de reserva ${ }^{12}$ y el salario de mercado (Todaro, 1969). El salario de reserva puede disminuir si los ingresos no salariales lo hacen y, por lo tanto, incentivar la entrada de los individuos al mercado laboral (Cahuc y Zylberberg, 2004). Esto sucede con los desplazados, quienes al perder su capital, tierra y demás fuentes de

12 Salario de reserva: salario mínimo que el trabajador aceptará en el empleo que se le ofrece. ingresos tienen un salario de reserva bajo o, en algunos casos extremos, de cero (Romero, 2013). Por eso es común que en las familias desplazadas no solo el jefe de hogar ofrezca su trabajo, sino también lo hagan otros miembros de la familia en edad de trabajar (Ibáñez y Moya, 2010).

Esta situación debería causar que la TGP de las víctimas del desplazamiento sea mayor al del resto de la población y contribuir a una mayor TGP consolidada en las ciudades del país (Flórez, 2003). Sin embargo, contrario a lo que ocurre con la migración económica -en donde los migrantes tienen mayores tasas de participación que la población nativa (Silva y Guataquí, 2008)- estudios recientes han encontrado que la TGP de los desplazados (62\%) es similar a la nacional (64,5\%) (Red Ormet, 2014). Por lo que el efecto de la presión de los desplazados en la TGP de las ciudades no es significativo.

La explicación de este fenómeno podría estar, como se discutía en la sección anterior, en las dificultades de integración laboral que enfrentan los desplazados forzados. Estas víctimas, a pesar de las necesidades económicas que enfrentan y de tener un salario de reserva bajo o de casi cero, no participan en el mercado laboral de las ciudades. Esto no es una decisión propia de los desplazados, sino la consecuencia de las barreras que encuentran para acceder al mercado laboral. De esta forma, los desplazados abandonan el proceso de búsqueda de trabajo y dejan de ser parte de la fuerza laboral. No obstante, es necesario profundizar sobre esta hipótesis a través de estudios empíricos cuantitativos en las ciudades del país, en especial, en las ciudades con mayor presión de los desplazados.

\subsection{Tasa de subempleo de los desplazados forzados}

Las variables más comunes para analizar las deficiencias en la calidad del empleo son la tasa de informalidad y subempleo, que a la vez están estrechamente relacionadas. La tasa de informalidad captura de forma más adecuada los cambios en la demanda laboral, mientras que la tasa de subempleo (TS) refleja más adecuadamente 
el comportamiento de la oferta (Uribe et al., 2008). El DANE define al subempleo como: "El deseo manifestado por el trabajador de mejorar sus ingresos, el número de horas trabajadas o tener una labor más propia de sus personales competencias" (DANE, 2010, p. 5). Además, existen dos tipos de subempleo: el visible y el invisible. ${ }^{13}$

Como el desplazamiento forzado es un fenómeno que afecta principalmente a la oferta laboral de las ciudades, los posibles efectos de este deben ser más visibles en la TS. El bajo nivel educativo, la inexperiencia y la inestabilidad laboral de los hogares inciden negativamente en la TS (Uribe et al., 2008). Estas características son propias y definen en gran parte a las familias desplazadas (Lozano-Gracia et al., 2010). Por lo que la TS de los desplazados debería ser menor que la de la población nativa, sin embargo, es mayor. Según datos de la ECH, la tasa promedio de subempleo objetivo, entre 2001 y 2006, de los nativos de las principales ciudades de Colombia fue de $11,30 \%$, mientras que la de los desplazados fue de $14,57 \%$.

Esta evidencia empírica contradice los determinantes presentados por Uribe et al. (2008). Además, la TS de los migrantes económicos en este mismo periodo fue de $10,9 \%$, lo que confirma las diferencias que tienen ambos tipos de migrantes en su integración laboral. Esto puede ser debido a que, si bien los desplazados tienen menor formación para los trabajos que desempeñan en las ciudades, desean tener una labor más apropiada para sus conocimientos agropecuarios. Por lo que, a pesar de su bajo nivel de formación, los desplazados consideran que tienen un empleo inadecuado. Sin embargo, es necesario comprobar esta hipótesis con estudios empíricos.

13 El primero se refiere a los trabajadores cuya jornada laboral es menor a la que quisieran tener. El segundo, corresponde a los trabajadores que ganan menos de lo que esperan o se desempeñan en actividades en donde no usan adecuadamente sus competencias profesionales.

\subsection{Dificultades en los estudios sobre los efectos de los desplazados en el mercado laboral de las ciudades receptoras}

Los efectos del desplazamiento forzado no terminan con las víctimas directas. La llegada de cientos de miles de desplazados a las principales ciudades del país, sin duda, afecta a las dinámicas en estos mercados laborales. Mercado laboral que, como se ha expuesto, tiene un importante vínculo con el proceso migratorio (ya sea forzado o voluntario). Sin embargo, la revisión de la literatura existente sobre el desplazamiento forzado, en Colombia, permite afirmar que existe una escasez de estudios sobre los efectos del desplazamiento en el mercado laboral de las comunidades receptoras.

Si bien en el país existe una cantidad considerable de estudios sobre las condiciones socioeconómicas de los desplazados y el impacto que causa el desplazamiento en las zonas de origen, solo existen unos pocos estudios que tengan en cuenta los efectos cualitativos en el mercado laboral de destino y menos aún que realicen estimaciones cuantitativas. Son pocos los trabajos, como el de Calderón e Ibáñez (2009), que estimen estos efectos. Esta situación se explica, en parte, por los problemas metodológicos existentes en el estudio de este fenómeno. En especial, los relacionados con el uso de la correlación espacial.

Primero, las ciudades del país llevan mucho tiempo recibiendo miles de desplazados cada año. El país se ha habituado a un modus vivendis permanente de violencia, que ha perpetuado sus estructuras sociales, económicas y políticas, y del cual hace parte el desplazamiento forzado. Entonces es más probable que ocurran ajustes entre las economías regionales, que disipen los efectos de los desplazados por toda la economía nacional. Los desplazados pueden provocar que individuos en condiciones parecidas, y con similar capacitación y nivel de educación regulen sus decisiones migratorias. Por lo que pueden dejar de desplazarse hacia ciudades en donde perciban que su ingreso esperado ha disminuido o dejar su actual residencia por la llegada de un alto volumen de desplazados. Compensación que también hacen otras cohortes de migrantes forzados. De hecho, en el 
periodo 2000-2005, cuando hubo el mayor pico en el número de desplazados, en el país, la migración voluntaria entre departamentos disminuyó casi un 50\% (Villarraga, 2015).

Segundo, más allá de la discusión sobre la causa del desplazamiento -si los desplazados eligen por sí mismos desplazarse o no- el destino de la migración es una decisión endógena de las víctimas. En la toma de esta decisión, las víctimas actúan de acuerdo a sus expectativas laborales, seguridad y la información obtenida a través de contactos personales, familiares y amigos (Goodman, 1981). Situación que también crea parcialidad hacia las opciones de destino más cercanas (Morrison, 1977). De esta forma, la distribución de los desplazados por el país no es aleatoria. Presumiblemente, los desplazados se ubican en los mercados laborales cercanos con una demanda laboral creciente, sesgando la estimación de sus efectos. Lo que causaría correlaciones positivas espurias entre la migración y variables claves del mercado laboral.

Algunos estudios han superado este problema de endogenización haciendo uso de variables instrumentales. Por ejemplo, en sus estudios sobre los efectos de la migración económica en mercados laborales regionales, Card (1990) y Lalonde y Topel (1991), usaron flujos migratorios pasados para instrumentalizar la localización de los migrantes. Más específicamente con la migración forzada, otros estudios también han hecho uso de este recurso. En Alemania, Bauer, Flake y Sinn (2011) utilizaron la proporción de edificios antiguos; en Suecia, Edin, Fredriksson y Åslund (2003), la imposición de las autoridades gubernamentales y en Colombia, Calderón e Ibáñez (2009), usaron el número de masacres perpetradas por los grupos armados en cada municipio de origen, ponderadas por la distancia al sitio de destino. Sin embargo, los problemas fundamentales persisten.

El estudio de los efectos de la migración interna -en este caso, forzada-, a través de la dispersión geográfica, no es efectivo: los mercados locales tienen muchas formas de ajustarse como para ser un análogo de una economía cerrada. Debido a estas complicaciones, el desplazamiento forzado debe ser estudiado de forma más holística y entenderlo como parte del ajuste economía-conflicto del país. No verlo como un choque en el corto plazo, en el mercado laboral de las ciudades, sino como un flujo poblacional constante desde el campo a las ciudades. Además, se deben tener en cuenta otros elementos que influyen cuantitativa y cualitativamente en los efectos, como se ha mencionado, la presión de los desplazados, las barreras de acceso al mercado laboral, las características socioeconómicas de la población afectada y la heterogeneidad regional del mercado laboral en Colombia (Arango, 2011). A pesar de estos problemas, es posible observar algunas relaciones entre el número de desplazados en una ciudad y las variables del mercado laboral.

\section{Conclusiones}

El artículo analizó la integración de los desplazados en los mercados laborales de las principales ciudades del país y los posibles efectos que tienen en algunas variables claves de este mercado, desde un análisis de las dinámicas de los movimientos de los migrantes forzados regionales -en especial la relación campo-ciudad-, y una comparación teórica entre la migración forzada y la migración económica. Se muestra que los desplazados fallan en su integración económica como consecuencia de los obstáculos adicionales que enfrentan para trabajar. Además, que la estimación de los efectos de esta integración aún es ambigua.

Las teorías migratorias desarrolladas en economía son útiles para entender las dinámicas del desplazamiento forzado, más aún cuando desarrollos recientes han reducido la distancia teórica entre la migración forzada y económica. Específicamente en el estudio de la integración y efectos de los desplazados, la teoría económica es útil para entender las características y limitantes adicionales que ellos enfrentan. Además, cómo estos factores afectan su posterior integración y efectos económicos en el lugar de acogida. Sin embargo, dicha compatibilidad teórica también se extiende a los problemas metodológicos existentes en la estimación de los efectos cuantitativos: endogeneidad de la decisión migratoria 
y los ajustes regionales. Lo que causa que haya resultados ambiguos sobre los efectos empíricos de los desplazados en los mercados laborales receptores.

En Colombia, este fenómeno es interno y afecta a todo el país. Si bien no causa grandes movimientos poblaciones entre departamentos, sí genera concentración en las principales ciudades del país, a pesar de no ser el destino preferido de los desplazados. De estas, las más afectadas son las ciudades intermedias, debido al alto volumen relativo de desplazados que reciben. En consecuencia, futuros estudios sobre el desplazamiento forzado se deben enfocar en las ciudades intermedias, principalmente: Florencia, Popayán, Quibdó, Santa Marta y Riohacha.

Los migrantes voluntarios y forzados comparten muchas características, sin embargo, tienen diferencias que explican sus dificultades para acceder a los mercados laborales. Mientras los migrantes económicos encuentran barreras principalmente al momento de desplazarse, los desplazados lo hacen al momento de acceder al mercado laboral. Además, la naturaleza del desplazamiento forzado obliga a migrar a los individuos más vulnerables, contrario a la migración económica, donde solo los más aptos lo hacen. Esta situación causa que los desplazados queden marginados y caigan en trampas de pobreza.
De igual forma, los impactos de esta fallida integración laboral en las principales ciudades de Colombia aún no son claros. Los ajustes de los mercados regionales, el origen endógeno de la decisión migratoria y la falta de datos, hacen que las estimaciones cuantitativas de los efectos, en las principales variables del mercado laboral, aún no sean concluyentes. Sin embargo, se teoriza sobre algunos efectos esperados. Se encontró que los desplazados tienen similar TGP que el resto de la población, a pesar de tener un menor salario de reserva. Además de que tienen una mayor TS que el resto de la población, a pesar de estar menos calificados.

Para finalizar, si bien esta investigación solo logra teorizar sobre algunos efectos de la integración de los desplazados en los mercados laborales de las ciudades colombianas, es importante que futuras investigaciones profundicen estos análisis. En especial, trabajos que realicen estimaciones fiables sobre la integración laboral de los desplazados y la magnitud de sus efectos laborales. La continuación de estos trabajos es necesaria para aclarar las dinámicas del conflicto y las consecuencias del drama humanitario del desplazamiento forzado, más ahora cuando el país está en una fase de posconflicto con las Farc y está exigiendo claridad sobre las implicaciones del desplazamiento forzado en la sociedad colombiana.

\section{Anexos}

\begin{tabular}{|c|c|c|c|c|c|}
\hline \multicolumn{6}{|c|}{ Anexo A. Resultados prueba diferencia de medias muestras dependientes } \\
\hline Departamento & Región & $\begin{array}{c}\text { Regiones según Grana- } \\
\text { da (2008) }\end{array}$ & P-valor & $\begin{array}{c}\text { Media de las } \\
\text { diferencias }\end{array}$ & $\begin{array}{r}\text { Cambio } \\
\text { poblacional } \\
\end{array}$ \\
\hline Archipiélago & Caribe & N.A. & 0,002001 & $-7,818$ & Aumento \\
\hline Magdalena & Caribe & & 0,008653 & 2826,223 & Aumento \\
\hline Cesar & Caribe & Norte & 0,006276 & 1810,033 & Disminución \\
\hline La Guajira & Caribe & & 0,1804 & $-374,7667$ & Nulo \\
\hline Córdoba & Caribe & & 0,7297 & $-168,2667$ & Nulo \\
\hline Bolívar & Caribe & Montes de María & 0,0003117 & 4713,533 & Disminución \\
\hline Sucre & Caribe & & 0,03574 & $-1541,8$ & Nulo \\
\hline Atlántico & Caribe & & 0,0001868 & $-6913,069$ & Aumento \\
\hline Antioquia & Andina & Urabá & 0,2055 & 1483,3 & Nulo \\
\hline Chocó & Pacífica & & 0,001524 & 5254,4 & Disminución \\
\hline
\end{tabular}


Germán Darío Valencia-Agudelo • Juan David Montoya-Polanco • Davidson Loaiza-Mejía

\begin{tabular}{|c|c|c|c|c|c|}
\hline \multicolumn{6}{|c|}{ Anexo A. Resultados prueba diferencia de medias muestras dependientes } \\
\hline Departamento & Región & $\begin{array}{c}\text { Regiones según Grana- } \\
\text { da (2008) }\end{array}$ & P-valor & $\begin{array}{l}\text { Media de las } \\
\text { diferencias }\end{array}$ & $\begin{array}{r}\text { Cambio } \\
\text { poblacional }\end{array}$ \\
\hline Valle del Cauca & Pacífica & & 0,001471 & $-3137,067$ & Aumento \\
\hline Risaralda & Andina & Cañón de las garrapatas & 0,05396 & $-1288,867$ & Aumento \\
\hline Caldas & Andina & & 0,0137 & 969,1333 & Disminución \\
\hline Quindío & Andina & & 0,003354 & $-1200,1$ & Aumento \\
\hline Tolima & Andina & & 0,04988 & 3984,967 & Disminución \\
\hline Huila & Andina & & 0,0002071 & $-1297,533$ & Aumento \\
\hline Caquetá & Amazonía & Sur & 0,06004 & 3523,3 & Disminución \\
\hline Putumayo & Amazonía & & 0,0001598 & 3118,767 & Disminución \\
\hline Nariño & Pacífica & & 0,05087 & 1363,867 & Disminución \\
\hline Cauca & Pacífica & & 0,008278 & 2512,533 & Disminución \\
\hline Amazonas & Amazonía & & 0,9923 & $-0,08$ & Nulo \\
\hline Guaviare & Amazonía & & 0,01693 & 1329,233 & Disminución \\
\hline Guainía & Amazonía & Antiguos territorios & 0,001224 & $-80,64286$ & Aumento \\
\hline Vaupés & Amazonía & nacionales & 0,0003514 & 118,3793 & Diminución \\
\hline Vichada & Orinoquía & & 0,001811 & 462,3448 & Disminución \\
\hline Cundinamarca & Andina & & 0,01341 & $-1145,767$ & Aumento \\
\hline Boyacá & Andina & & $0,7001^{*}$ & 2356667 & Aumento \\
\hline Meta & Orinoquía & Centro & 0,6567 & $-96,86667$ & Aumento \\
\hline Casanare & Orinoquía & & 0,6954 & 41,46667 & Nulo \\
\hline Bogotá & Andina & & 0,01229 & $-15712,8$ & Aumento \\
\hline Arauca & Orinoquía & & 0,0001008 & 1160,7 & Disminución \\
\hline Santander & Andina & Nororiente & 0,0001306 & $-2334,933$ & Aumento \\
\hline Norte de Santander & Andina & & 0,02478 & 559,5667 & Disminución \\
\hline
\end{tabular}

\section{Referencias}

Ackah, C. y Medvedev, D. (2010). Internal Migration in Ghana Determinants and Welfare Impacts. Legon, Ghana: The World Bank, West Africa Poverty Reduction and Economic Management Unit.

Altonji, J. G. y Card, D. (1991). The Effects of Immigration on the Labor Market Outcomes of Less-skilled Natives. En J. M. Abowd y R. B. Freeman (Eds.), Immigration, Trade, and the Labor Market (pp. 209233). Chicago, U.S.: The University of Chicago Press.

Arango, J. (2003). La explicación teórica de las migraciones: luz y sombra. Migración y Desarrollo, (1), $1-30$.

Arango, L. E. (2011). Mercado de trabajo de Colombia: suma de partes. Bogotá, Colombia: Banco de la República.

Bauer, T. K., Flake, R. y Sinn, M. G. (2011). Labor Market Effects of Immigration Evidence from Neighborhood Data. Canberra, Australia: Australian National University, Department of Economics. 
Becker, G. S. (1975). Human Capital: A Theoretical and Empirical Analysis, with Special Reference to Education, Second Edition. New York/London, US/UK: Columbia University Press.

Bernal, R. (2009). The Informal Labor Market in Colombia: Identification and Characterization. Desarrollo y Sociedad, (63), 145-208.

Blanco, C. (2000). Las migraciones contemporáneas. Madrid, España: Alianza.

Bonilla, R. (2004). El desplazamiento forzado interno en Colombia. Observatorio de coyuntura socioeconómica, 12. Bogotá, Colombia: OCSE.

Borjas, G. (1994). The Economics of Immigration. Journal of Economic Literature, 32(4), 1667-1717.

Borjas, G. (2003). The Labor Demand Curve is Downward Sloping: Reexamining the Impact of Immigration on the Labor Market. Quarterly Journal of Economics, 118(4), 1335-1374.

Borjas, G., Freeman, R. B. \& Katz, L. F. (1997). How Much Do Immigration and Trade Affect Labor Market Outcomes? Brookings Papers on Economic Activity, (1), 1-90.

Cahuc, P. y Zylberberg, A. (2004). Labor Economics. Cambridge, Massachusetts: The MIT Press.

Calderón, V. e Ibáñez, A. M. (2009). Labor Market Effects of Migration-Related Supply Shocks: Evidence from Internally Displaced Populations in Colombia. Documentos CEDE. Bogotá, Colombia: Universidad de los Andes.

Card, D. (1990). The impact of the Mariel Boatlift on the Miami Labor Market. Industrial and Labor Relations Review, 43(2), 245-257.

Casasfranco, M. V. (2002). Las migraciones y los desplazamientos forzados: Análisis comparativo e integral desde un enfoque de derechos humanos (Retos en Centroamérica y Colombia). San José, C. R.: Impresora Obando.

Chiswick, B. R. (1978). The Effect of Americanization on the Earnings of Foreign-born Men. Journal of Political Economy, 86(5), 897-921.

Clifford, J. (1970). Some sociological aspects of migration. Rural Sociology, (35), 523-33.

CNMH -Centro Nacional de Memoria Histórica-. (2015). Una nación desplazada: informe nacional desplazamiento forzado en Colombia. Bogotá, Colombia: CNMH - UARIV.

CONAPO -Consejo Nacional de Población-. (2010). Índices de intensidad migratoria México-Estados Unidos 2010. Colección: Índices sociodemográficos. México D.F., México: Consejo Nacional de Población.

DANE -Departamento Administrativo Nacional de Estadística- y UARIV -Unidad para la Atención y Reparación Integral a las Victimas-. (2015). Encuesta de Goce Efectivo de Derechos. Bogotá, Colombia: DANE.

DANE -Departamento Administrativo Nacional de Estadística-. (2010). Gran Encuesta Integrada de Hogares (GEIH). Recuperado de https://www.dane.gov.co/files/noticias/presentacion_lacea_ medellin.pdf

Davenport, C., Moore, W. y Poe, S. (2003). Sometimes You Just Have to Leave: Domestic Threats and Forced Migration, 1964-1989. International Interactions, 29(1), 27-55. 
Germán Darío Valencia-Agudelo • Juan David Montoya-Polanco • Davidson Loaiza-Mejía

Devillanova, C. y García, W. (1998). Migration across Spanish Provinces: Evidence from the Social Security Records (1978-1992). Barcelona, España: Universitat Pompeu Fabra.

Dustmann, C., Glitz, A. y Frattini, T. (2008). The Labour Market Impact of Immigration. London, U.K.: Centre for Research and Analysis of Migration, Department of Economics, University College London.

Edin, P. A., Fredriksson, P. y Åslund, O. (2003). Ethnic Enclaves and the Economic Success of Immigrants-Evidence from a Natural Experiment. Quarterly Journal of Economics, 118(1), 329-357.

Egea, C. y Soledad, J. I. (2008). Migraciones y conflictos. El desplazamiento interno en Colombia. Convergencia. Revista de Ciencias Sociales, (47), 207-235.

Engel, S. e Ibáñez, A. M. (2007). Displacement Due to Violence in Colombia: A Household-Level Analysis. Economic Development and Cultural Change, 55(2), 335-365.

Flórez, C. E. (2003). Migration and the Urban Informal Sector in Colombia. Bogotá, Colombia: Universidad de los Andes. Recuperado de http://citeseerx.ist.psu.edu/viewdoc/ download?doi=10.1.1.197.7013\&rep=repı\&type=pdf

Forman, S. H. (1975). Migration: a problem in conceptualization. Rice University Studies, (62), 25-35.

Galvis, L. A. (2002). Determinantes de la migración interdepartamental en Colombia, 1988-1993. Cartagena, Colombia: Banco de la República.

Gónzales, J. I. y Mendoza, A. M. (2010). El desplazamiento forzado en Colombia y la intervención del Estado: una mirada desde el goce efectivo de derechos y los factores asociados a su realización. Documentos CEDE. Bogotá, Colombia: Universidad de los Andes.

Goodman, J. L. (1981). Information, Uncertainty, and the Microeconomic Model of Migration Decision Making. London, UK: Center for Population Research, National Institute of Child Health and Human Development.

Grossman, J. B. (1982). The Substitutability of Natives and Immigrants in Production. The Review of Economics and Statistics, 64(4), 596-603.

Guataquí, J. C. (2006). Forced displacement and internal migration in Colombia: 1992-2004. Warwick, UK: University of Warwick, Department of Sociology.

Guerra, Á. y Juárez, F. (2011). Características Socioeconómicas y Salud en Personas Pobres y Desplazadas. Psicologia: Teoria e Pesquisa, 27(4), 511-519.

Herrera, R. (2006). La perspectiva teórica en el estudio de las migraciones. México D. F., México: Siglo XXI Editores.

Ibáñez, A. M. y Moya, A. (2010). Do Conflicts Create Poverty Traps? Asset Losses and Recovery for Displaced Households in Colombia. En R. Di Tella, S. Edwards y E. Schargrodsky, The Economics of Crime: Lessons for and from Latin (pp. 137-172). Chicago, U.S.: University of Chicago Press.

Ibáñez, A. M. y Querubín, P. (2004). Acceso a tierras y desplazamiento forzado en Colombia. Documento CEDE ${ }^{\circ}$ 23. Bogotá, Colombia: Universidad de los Andes. 
Ibáñez, A. M. y Velásquez, A. (2008). El impacto del desplazamiento forzoso en Colombia: condiciones socioeconómicas de la población desplazada, vinculación a los mercados laborales y políticas públicas. Santiago, Chile: Naciones Unidas, División de Desarrollo Social.

IDMC -Internal Displacement Monitoring Centre-. (2016). Internal Displacement Monitoring Centre. Recuperado de http://www.internal-displacement.org/database

Justino, P. (2012). War and Poverty. En M. R. Garfinkel y S. Skaperdas, The Oxford Handbook of the Economics of Peace and Conflict (pp. 676- 705). Oxford, US: Oxford University Press.

Kuhlman, T. (2000). Forced migration: an economist's perspective. Amsterdam, Netherlands: University Amsterdam, Faculty of Economics, Business Administration and Econometrics.

Lalonde, R. J. y Topel, R. H. (1991). Labor Market Adjustments to Increased Immigration. En J. M. Abowd y R. B. Freeman (Eds.), Immigration, Trade and the Labor Market (pp. 167-199). Chicago, US: University of Chicago Press.

Lee, E. S. (1966). A Theory of Migration. Demography, 3(1), 47-57.

Lozano-Gracia, N., Piras, G., Ibáñez, A. M. y Hewings, G. J. (2010). The Journey to Safety: Conflict-Driven Migration Flows in Colombia. International Regional Science Review, 33(2), 157-180.

Lucas, R. E. (1997). Internal Migration in Developing Countries. En M. Rosenzweig, y O. Stark, Handbook of Population and Family Economics (pp. 721-787). Boston, US: Elsevier Science, Boston University.

Massey, D. S., Arango, J., Hugo, G., Kouaouci, A., Pellegrino, A. y Taylor, J. E. (1993). Theories of International Migration: A Review and Appraisal. Population and Development Review, 19(3), 431-466.

Morrison, P. A. (1977). Functions and Dynamics of the Migration Process. En A. A. Brown y E. Neuberger, Internal Migration: A Comparative Perspective (pp. 61-72). New York, US: Academic Press.

Naranjo, G. (2004). Ciudadanía y desplazamiento forzado en Colombia: una relación conflictiva interpretada desde la teoría del reconocimiento. Estudios Políticos, (25), 137-160.

OIM -Organización Internacional para las Migraciones-. (2001). Informe sobre las migraciones en el mundo 2000. Vol. 4 - Serie de la OIM de Informes sobre Migración. Geneva, Suiza: OIM, ONU.

PNUD -Programa de las Naciones Unidas para el Desarrollo-. (2014). Boletín 1. Bogotá, Colombia: Departamento Nacional de Planeación.

Poulain, M. y Perrin, N. (2001). Is the measurement of international migration flows improving in Europe. Geneva, Suiza: UN Statistical Commission and Statistical Office of the UN Economic Commission for European Communities.

Ravenstein, E. G. (1885). The Laws of Migration. Journal of the Statistical Society of London, 48(2), 167-235.

Red Ormet. (2014). Población desplazada y mercado. Boletín No. 1 - Boletín Nacional. Bogotá, Colombia: PNUD.

Restrepo, J. A. y Sadinle, M. (2009). Grupos armados y tenencia de tierras en el desplazamiento forzado interno en Colombia: una aproximación desde la población atendida por la Iglesia católica colombiana. Bogotá, Colombia: Facultad de Ciencias Económicas y Administrativas, Pontificia Universidad Javeriana. 
Germán Darío Valencia-Agudelo • Juan David Montoya-Polanco • Davidson Loaiza-Mejía

RNI -Red Nacional de Información-. (2016). Registro Único de Víctimas (RUV). Recuperado de https:// www.unidadvictimas.gov.co/es/registro-unico-de-victimas-ruv/37394

Romero, A. M. (2013). Informalidad laboral en los centros urbanos de Colombia: ¿Depende del desplazamiento forzado? Bogotá, Colombia: Pontificia Universidad Javeriana.

Ruhs, M. y Vargas, C. (2015). The Labour Market Effects of Immigration. The Migration Observatory. Recuperado de https://migrationobservatory.ox.ac.uk/resources/briefings/ the-labour-market-effects-of-immigration/

Sales, R. (2007). Understanding immigration and refugee policy. Bristol, UK: Policy Press.

Silva, A. C. y Guataquí, J. C. (2008). Caracterización instrumental del desplazamiento forzado en Colombia: hechos estilizados y la Encuesta Continua de Hogares (2001-2006). Revista de Ciencias Sociales (RCS), XIV(3), 439-452.

Silva, A. C. y Sarmiento, J. A. (2013). Desplazados forzados y su participación en el mercado laboral colombiano. Revista de la Facultad de Ciencias Económicas de la Universidad Militar, XXI(1), 167-187.

Sjaastad, L. A. (1962). The Costs and Returns of Human Migration. Journal of Political Economy, (70), 80-93.

Stark, O. (1991). The Migration of Labor. Cambridge/Oxford, US/UK: B. Blackwell.

Stouffer, S. (1940). Intervening Opportunities: A Theory Relating Mobility and Distance. American Sociological Review, 5(6), 845-867.

Tobler, W. (1970). A Computer Movie Simulation Urban Growth in the Detroit Region. Economic Geography, 46(2), 234-240.

Todaro, M. P. (1969). A Model of Labor Migration and Urban Unemployment in Less Developed Countries. The American Economic Review, 59(1), 138-148.

UNHCR -United Nations High Commissioner for Refugees-. (2015). UNHCR Statistical Yearbook 2014, 14th edition. Ginebra, Suiza: UNHCR. Recuperado de http://www.internal-displacement.org/ americas/colombia/

Uribe, M. T. (2002). Notas para la conceptualización del desplazamiento forzado en Colombia. Medellín, Colombia: Instituto de Estudios Políticos de la Universidad de Antioquia.

Uribe, J. I., Ortiz, C. H. y García, G. A. (2008). Informalidad y subempleo en Colombia: dos caras de la misma moneda. Cuadernos de Administración, 21(37), 211-241.

Villarraga, H. G. (2015). Migración interna, movilidad residencial y dinámicas metropolitanas en Colombia. Barcelona, España: Universidad Autónoma de Barcelona.

Walker, R., Ellis, M. y Barff, R. (1992). Linked Migration Systems: Immigration and Internal Labor Flows in the United States. Economic Geography, 68(3), 234-248.

Zipf, G. K. (1946). The P1 P2/D Hypothesis: On the Intercity Movement of Persons. American Sociological Review, 11(6), 677-686. 